\title{
Familial Cerebral Aneurysms
}

\author{
Richard Leblanc
}

\begin{abstract}
Familial cerebral aneurysms are currently the subject of burgeoning interest. We review the pertinent, recent reports on this topic in the light of our study of 17 families with familial cerebral aneurysms. The prevalence of familial cerebral aneurysms ranges from 5-28\%. The sex distribution displays a female bias. Mothers are more often affected than fathers and daughters more than sons. There is no site predilection for familial cerebral aneurysms but they tend to occur at the same (or mirror) site within families. The age at rupture of familial cerebral aneurysms is younger, especially in females, than for sporadic aneurysms. They tend to rupture within the same decade in families, and within five years of each other in identical twins. The size of ruptured familial cerebral aneurysms appears to be smaller, especially in women, than sporadic aneurysms. The pattern of inheritance is unknown. A poor outcome of rupture is more frequent in familial cerebral aneurysms cases than in sporadic ones. Angiographic screening of family members at risk, especially first degree relatives, appears justified.
\end{abstract}

RÉSUMÉ: Anévrismes cérébraux familiaux. Les anévrismes cérébraux familiaux font actuellement l'objet d'un intérêt croissant. Nous revoyons les rapports récents sur ce sujet à la lumière de notre étude de 17 familles présentant des anévrismes cérébraux familiaux. La prévalence des anévrismes cérébraux familiaux varie de 5 à $28 \%$. La répartition selon le sexe montre une prévalence plus élevée chez la femme. Les mères sont plus souvent atteintes que les pères et les filles plus souvent que les fils. Il n'y a pas de site de prédilection pour les anévrismes cérébraux familiaux, mais ils ont tendance à se situer au même endroit (ou en miroir) dans les familles. L'âge au moment de la rupture des anévrismes cérébraux familiaux est plus précoce, surtout chez les femmes, que pour les anévrismes sporadiques. Ils ont tendance à se rupturer dans la même décennie dans les familles et en dedans de cinq ans chez les jumeaux identiques. La taille des anévrismes cérébraux familiaux rupturés semble être plus faible, surtout chez les femmes, que celle des anévrismes sporadiques. Le mode d'hérédité est inconnu. Une issue défavorable de la rupture est plus fréquente dans les anévrismes cérébraux familiaux que dans les cas sporadiques. Le dépistage angiographique des membres des familles à risque, surtout des apparentés au premier degré, semble justifié.

Can. J. Neurol. Sci. 1997; 24: 191-199

As with people who have a family history of cancer or anemia, I felt burdened by the blood flowing in my veins, my inevitable destiny.

\section{B. Yoshimoto in Blood and Water}

Cerebral aneurysms most likely result from atherosclerotic degeneration of the cerebral arterial wall. ${ }^{2}$ The identification of familial clusters of cerebral aneurysms and the demonstration that these lesions and the patient who harbour them have biological characteristics distinct from sporadic cases suggests a possible genetic etiology for familial cerebral aneurysms, and a possible genetic contribution to the formation of sporadic aneurysms as well. The possibility that cerebral aneurysms may be congenital was first suggested by Gull, in 1859, who, unable to identify a structural causative lesion in cerebral aneurysms examined at autopsy suggested that aneurysms result from an inborn defect in the arterial wall. ${ }^{2}$ Forbus, in 1930 , added support to the congenital theory by demonstrating presumably congenital defects in the wall of cerebral arteries. ${ }^{3} \mathrm{He}$ postulated that these mural defects produce areas of decreased resistance to arterial pressure, that he termed loci minoris recistentia that, he felt, would be especially vulnerable to the haemodynamic stresses of the arterial pressure and would ultimately result in the formation of cerebral aneurysms. However, Stehbens has demonstrated that the areas of mural defects are widespread in the cerebral arterial tree and that aneurysms develop not within them, but beside them at areas of bifurcations where haemodynamic stresses are the greatest ${ }^{2}$ and recent studies have demonstrated histological changes associated with cerebral aneurysms that are indistinguishable from early atherosclerotic changes. ${ }^{2}$ Thus the congenital theory of cerebral aneurysm gains no support from ultrastructural examination. Other factors invoked in the support of the congenital theory are the occurrence of multiple cerebral aneurysms, the variations of the circle of Willis associated with cerebral aneurysms, and the suggestion that aneurysms develop at sites of persistence of embryonic anasto-

From the Montreal Neurological Hospital, Department of Neurology \& Neurosurgery, McGill University, Montreal.

RECEIVED SEPTEMBER 25, 1996. ACCEPTED IN FINAL FORM FEBRUARY 27, 1997. Reprint requests to: Richard Leblanc, M.D., 3801 University Street, Montreal. Quebec. Canada H3A 2B4 
moses or at sites of incomplete involution of embryonic vessels. All of these features have also been challenged, most notably by Stehbens. ${ }^{2}$

The strongest evidence that some cerebral aneurysms may have a genetic component in their etiology is suggested by their occurrence in families, ${ }^{4-14}$ in identical twins, ${ }^{15-21}$ and in association with genetically-determined conditions such as adult polycystic kidney disease (APKD). ${ }^{22-24}$ For the purpose of this review (and our epidemiological studies) we consider as familial cases instances where at least 2 first, second or third degree relatives have a proven cerebral aneurysm.

In this report we review the significant papers addressing familial cerebral aneurysms and comment on them in the light of our own study of 17 families with cerebral aneurysms. These families include 39 patients who harboured 46 cerebral aneurysms and 46 asymptomatic relatives who were electively screened by intra-arterial digital subtraction angiography (IADSA), or by magnetic resonance angiography (MRA). The first 14 families have been previously described in detail elsewhere, the 3 others are summarized in Figure 1, and pertinent epidemiological data on the 17 families is presented in Table $1 .^{6,14}$

\section{Familial Aggregations of Cerebral Aneurysms}

Familial aggregations of cerebral aneurysms may result from their association with a known hereditary syndrome such as APKD, ${ }^{22-24}$ may be a fortuitous occurrence, or may reflect the true inheritance of an abnormal gene or genes predisposing to aneurysm formation. ${ }^{25}$ Norrgärd et al., in a mail survey of relatives of patients with a cerebral aneurysm, have estimated the prevalence of familial cerebral aneurysms in Sweden at 5\%. Ronkainen et al., in the largest prospective study to date, have identified a familial history in $9 \%$ of Finns with a cerebral aneurysm. ${ }^{7}$ Wang et al. identified an $11.4 \%$ risk of familial sub-

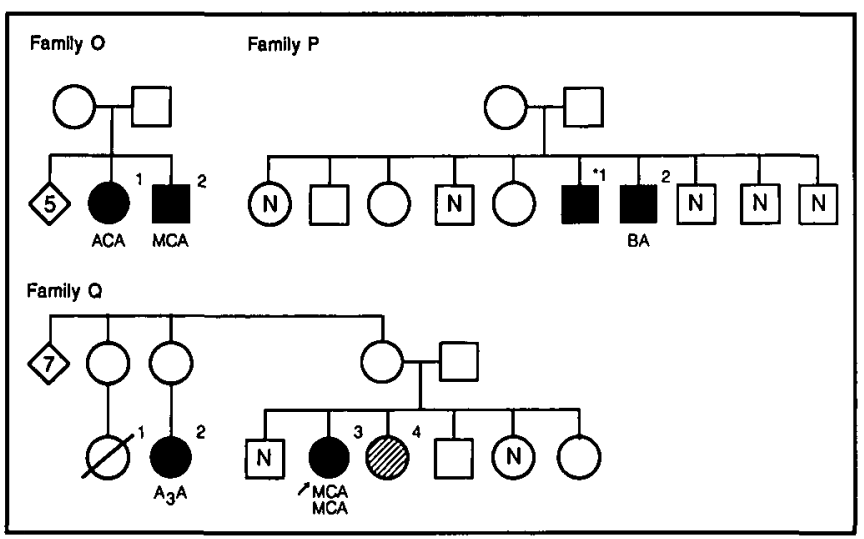

Figure 1: Pedigree of three previously unreported families. The circles indicate females, the squares males, and the diamonds male and female siblings. The presence of a documented cerebral aneurysm is indicated by black squares and circles. The circle with a line through it indicates a suspected cerebral aneurysm and the circle with the hatching indicates a patient with a documented subarachnoid haemorrhage who died before angiography could be performed and in whom autopsy was refused. These 2 patients are recorded but excluded from study. ACA: anterior communicating artery aneurysm, $A_{3} A$ : pericallosal artery aneurysm, MCA: middle cerebral artery aneurysm, BA: basilar artery aneurysm. The asterisk refers to a patient with a documented cerebral aneurysm whose site could not be ascertained from existing records. The arrow indicates a patient whose aneurysm was discovered by elective angiographic screening. All other aneurysms ruptured. arachnoid haemorrhage in Seattle, with no attempt to identify those patients with cerebral aneurysms, compared to $6.4 \%$ for the general population. ${ }^{8}$ Shievink et al. observed that $25 \%$ of patients with a cerebral aneurysm in Rochester, Minnesota, had a family history of cerebral aneurysms. ${ }^{9}$ In Canada, Mathieu et al, in a review of the medical records and pedigrees of patients with a cerebral aneurysm in the Saguenay-Lac St-Jean region, known for its high incidence of arterial hypertension, found that $27.2 \%$ had a family history ${ }^{12}$ (Figure 2). As is seen, many of the prevalence studies originate from communities with a high degree of relatedness due to geographic isolation or, as is the case with the Saguenay-Lac St-Jean region of Canada, include exceptionally large kindreds. In the Saguenay-Lac St-Jean region, De Braekeleer et al. have observed a risk ratio of 4.7 for the inheritance of cerebral aneurysms in first degree relatives, similar to the 4.1 reported by Schievink et al. in Rochester ${ }^{9,13}$ (Table 2). Second degree relatives from the Saguenay-Lac StJean region have a risk ratio of 2.1 and 3rd degree relatives 1.1. Bromberg et al. observed a risk ratio of 6.6 for subarachnoid hemorrhage in first and second degree relatives and estimate that first degree relatives are at 3-7 times greater risk than the general population, for a lifetime risk of SAH in first degree relatives of $2-5 \%^{10}$ (Table 2). Norrgård et al. and Wang et al. observed that arterial hypertension was not a factor to explain the familial clustering of cerebral aneurysms in their populations. ${ }^{5,8}$

\section{Age at first presentation}

Most studies have reported that familial cerebral aneurysms rupture at a younger age than do sporadic ones ${ }^{4,5,7,9,11}$ (Figure 3). Thus, in a review of the cases reported to 1986 we found that the average age at the time of aneurysm rupture was 42.3 years for familial cases versus 51.7 years for sporadic ones. ${ }^{4}$ In recent studies we observed that the peak decennial incidence of ruptured familial aneurysms was in the 5th decade compared to the 6 th for sporadic cases, and that by age 50 fully $70 \%$ of familial aneurysms had ruptured compared to $42 \%$ for sporadic ones. ${ }^{6,14}$ These differences were found to be statistically significant. Norrgård et al. observed an average age of 43.9 years for the rupture of a familial cerebral aneurysm, compared to 52.5 for sporadic ones but did not submit this difference to statistical analysis. ${ }^{5}$ Bromberg et al. observed an average age at the time of rupture of 46.6 years for familial aneurysms, significantly different from the 55.4 years for sporadic ones. ${ }^{11}$ These workers also observed that the average age of rupture in parents with a familial cerebral aneurysm was 49.7 years, significantly older than the average age of rupture, at 26.8 years, in their children. In our own cases the average age of rupture of parents with familial cerebral aneurysms was 55 years, compared to 37 years for their children. Bromberg et al. have attributed this age differential in succeeding generations as reflecting the phenomenon of anticipation, a term meant to denote earlier onset and worse outcome of the disease in successive generations. However, such a phenomenon may be wholly accounted for by ascertainment bias in that more severe cases are more likely to be identified while patients with milder, later onset disease are more likely to leave offspring. Ronkainen et al. and Schievink et al. observed a mean age of rupture for familial cases of 50 and 53 years respectively, compared to 52 and 55 years for sporadic cases. ${ }^{7,9}$ These differences were not significantly different. 


\begin{tabular}{|c|c|c|c|c|c|}
\hline $\begin{array}{l}\text { Affected } \\
\text { Individuals }\end{array}$ & Relationship & $\begin{array}{l}\text { Age at } \\
\text { Diagnosis } \\
\text { (years) }\end{array}$ & $\begin{array}{l}\text { Site of } \\
\text { Aneurysm }\end{array}$ & $\begin{array}{l}\text { Clinical } \\
\text { Presentation }\end{array}$ & Outcome \\
\hline$A-1$ & mother & 68 & $\mathrm{R} \& \mathrm{~L} M C A$ & $\begin{array}{l}\text { mass effect, } \\
\text { rupture }\end{array}$ & dead \\
\hline A-2 & daughter & 24 & $\begin{array}{l}\text { MCA, } \\
\text { R \& L ICA }\end{array}$ & rupture & well \\
\hline$A-3$ & daughter & 36 & ICA & elective screening & well \\
\hline B-1 & sister & 42 & $\mathrm{BA}$ & rupture $^{\circ}$ & well \\
\hline B-2 & sister & 34 & ICA & rupture & disabled \\
\hline C-1 & mother & 39 & ICA & rupture & dead \\
\hline $\mathrm{C}-2$ & daughter & 31 & $\mathrm{ACA}$ & rupture & well \\
\hline D-1 & mother & 55 & ICA & mass effect & well \\
\hline D-2 & son & 33 & $\mathrm{ACA}$ & rupture & well \\
\hline E-1 & sister & 62 & $\mathrm{ICA}$ & rupture & well \\
\hline E-2 & sister & 52 & $\mathrm{R} \& \mathrm{~L} M C A$ & rupture & dead \\
\hline F-1 & sister & 37 & ICA & rupture & dead \\
\hline $\mathrm{F}-2$ & brother & 62 & ICA & mass effect & well \\
\hline G-1 & sister & 51 & ICA & rupture & dead \\
\hline G-2 & brother & 53 & AchA & rupture & dead \\
\hline G-3 & brother & 54 & $\begin{array}{l}A_{3} A, \text { ICA } \\
R \text { \& L AchA }\end{array}$ & rupture & dead \\
\hline G-4 & sister & 57 & ICA & rupture & dead \\
\hline $\mathrm{H}-1$ & mother & 68 & ICA & rupture & dead \\
\hline $\mathrm{H}-2$ & daughter & 45 & ICA & rupture & disabled \\
\hline $\mathrm{I}-1$ & mother & 45 & $\mathrm{ACA}$ & rupture & dead \\
\hline $\mathrm{I}-2$ & son & 39 & ICA & rupture & dead \\
\hline $\mathrm{J}-1$ & sister & 60 & $\mathrm{MCA}$ & rupture & dead \\
\hline $\mathrm{J}-2$ & sister & 66 & $\mathrm{MCA}$ & rupture & dead \\
\hline $\mathrm{J}-3$ & niece & 33 & ICA & rupture & dead \\
\hline $\mathrm{K}-1$ & sister & 38 & ICA & rupture & dead \\
\hline K-2 & brother & 49 & $\mathrm{ACA}$ & rupture & dead \\
\hline L-1 & aunt & 40 & $\mathrm{ACA}$ & rupture & disabled \\
\hline L-2 & niece & 40 & MCA & rupture & dead \\
\hline M-1 & aunt & 75 & ICA & rupture & well \\
\hline M-2 & nephew & 47 & $\mathrm{BA}, \mathrm{MCA}$ & rupture & well \\
\hline $\mathrm{N}-1$ & sister & 17 & $\mathrm{ACA}$ & rupture & well \\
\hline $\mathrm{N}-2$ & sister & 29 & $\mathrm{ACA}$ & rupture & dead \\
\hline $\mathrm{N}-3$ & female cousin & 51 & $\mathrm{ACA}$ & rupture & dead \\
\hline $0-1$ & sister & 28 & $\mathrm{ACA}$ & rupture & well** \\
\hline $\mathrm{O}-2$ & brother & 42 & $\mathrm{MCA}$ & rupture & well \\
\hline P-1 & brother & 49 & unrecorded & rupture & dead \\
\hline P-2 & brother & 54 & BA & rupture & well \\
\hline Q-1 & female cousin & 60 & $\mathrm{~A}_{3} \mathrm{~A}$ & rupture & well \\
\hline $\mathrm{Q}-2$ & female cousin & 49 & $\mathrm{R}^{3} \& \mathrm{LMCA}$ & elective screening & well \\
\hline
\end{tabular}

*Affected individuals are labelled according to previous reports. ${ }^{6,14}$ When more than one aneurysm is listed the first one is the one that ruptured. $* *$ Died of ruptured aortic aneurysm.

$\mathrm{A}_{3} \mathrm{~A}$ : pericallosal artery; ACA: anterior cerebral artery; BA: basilar artery; MCA: middle cerebral artery; $\mathrm{R}=$ right, $\mathrm{L}=$ left.

Although most have observed a female preponderance for familial cerebral aneurysm, as discussed below, it appears that familial cerebral aneurysms rupture at a younger age in men than in women. Thus, we have observed that the average age of rupture of a familial cerebral aneurysm was 39.6 years for males and 44.6 for females. Others have made similar observations. ${ }^{4}$

An interesting finding is that familial aneurysms have a distinct predilection to rupture within the same decade in individuals of the same family: in $80 \%$ of sisters with a familial cerebral aneurysm rupture occurred within 10 years of each other (mean 6 years) compared to the $20 \%$ expected from two randomlyselected individuals with sporadic aneurysms ${ }^{6}$ (Figure 4). Similarly, in twins with cerebral aneurysms rupture occurred within the same decade, in most cases within 5 years, in all cases. ${ }^{15-21}$

\section{Gender}

All reports to date have identified a higher incidence of familial cerebral aneurysms in women than in men. The overrepresentation of women ranges from 52 to $80 \%$, the latter seen in our own study population. ${ }^{4,5,7,9,14} \mathrm{~A}$ female preponderance for familial cerebral aneurysms may, at first glance, not appear worthy of notice in that it is widely held that cerebral aneurysms in general are more common in women. We have addressed this question by comparing the sex and age at the time of first rupture in our familial patients to the patients reported in the First Cooperative Study on Aneurysmal Subarachnoid Hemorrhage. ${ }^{6}$ The latter study established the female preponderance for sporadic cerebral aneurysms but a feature that frequently escapes 


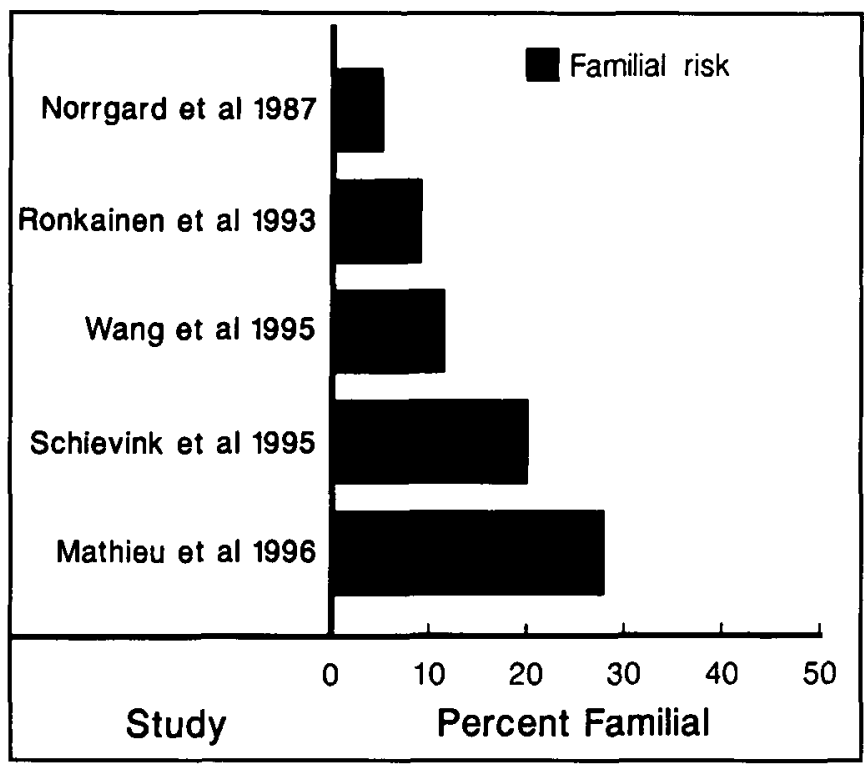

Figure 2: Familial risk of cerebral aneurysms reported in the literature. (The study by Wang et al. relates to familial subarachnoid haemorrhage.)

years or older. Below this age there is a distinct male predominance for sporadic cerebral aneurysms. We have observed that $80 \%$ of familial aneurysms in our study population occurred in women, versus the $59 \%$ expected for sporadic cases. ${ }^{6}$ This overrepresentation of women occurred below the age of 50 years where $78 \%$ of patients with familial aneurysms were women compared to $45 \%$ for sporadic aneurysms. Above this age there was no statistical difference in incidence of familial aneurysms in men or women compared to sporadic aneurysms. In women with familial aneurysms rupture occurred before the age of 50 in $59 \%$ of cases, compared to the expected $31 \%$ for sporadic aneurysms. Thus these data suggest that ruptured familial cerebral aneurysms are more common in females and that their rupture occurs at a younger age than the rupture of sporadic cerebral aneurysms.

\section{Multiplicity}

Perhaps contra-intuitively, multiple aneurysms have not been shown to be over-represented in families compared to the population with sporadic aneurysms. It is interesting to note, however, that most reports of multiple aneurysms, either familial or sporadic, have a clear female preponderance. Sixty percent of patients with multiple familial aneurysms in our cohort were women. ${ }^{6}$

\section{Site distribution of familial aneurysms}

Table 2: Risk Ratio (95\% Confidence Interval) for Subarachnoid Hemorrhage by Degree of Relatedness.

\begin{tabular}{ll}
$\begin{array}{l}\text { Bromberg et al., 1995 } \\
\quad \text { First degree }\end{array}$ & $6.6(2.0-21)$ \\
De Braekeleer et al., 1996 & \\
$\quad$ First degree & 4.7 \\
$\quad$ Second degree & 2.1 \\
$\quad$ Third degree & 1.1 \\
Schievink et al., 1995 & \\
$\quad$ First and second degree & $4.1(2.1-7.4)$ \\
\hline
\end{tabular}

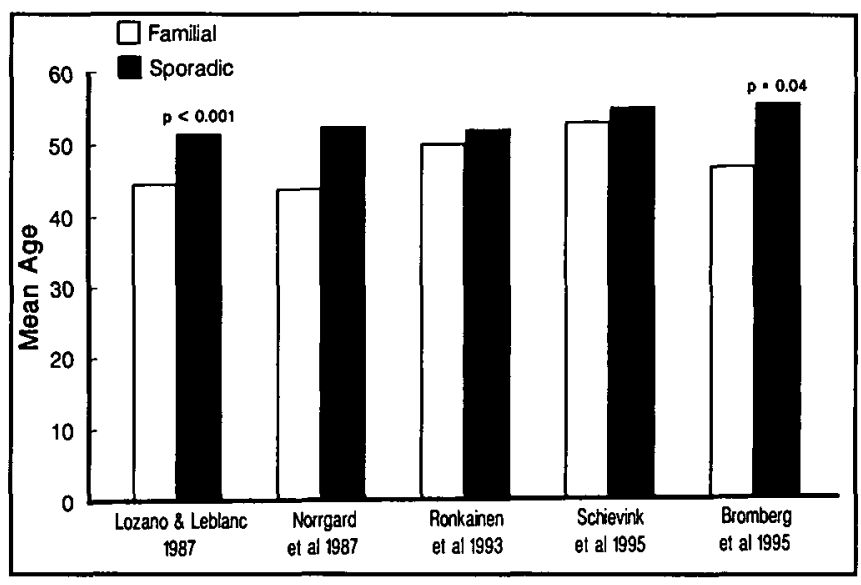

Figure 3: Mean age at rupture for familial and sporadic cerebral aneurysms. (The data from Bromberg et al. is for familial subarachnoid haemorrhage, most patients having a demonstrated cerebral aneurysm.)

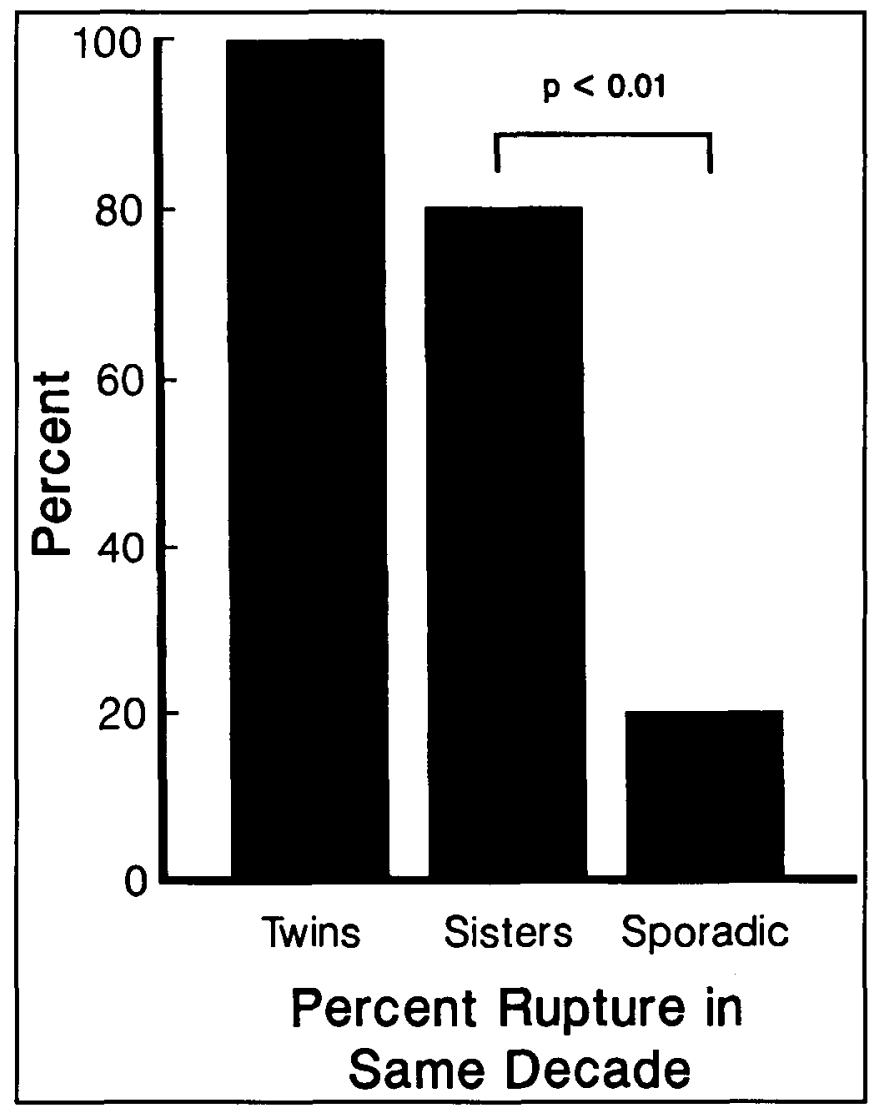

Figure 4: Percentage of familial cerebral aneurysms that rupture within the same decade, compared to two randomly chosen pairs of sporadic cerebral aneurysms. (Data from Lozano AM and Leblanc $R$, 1987 and Leblanc $R, 1996)^{6,14}$

We have previously reported that anterior communicating artery aneurysms may be less frequent in familial cases than in sporadic ones, and Shievink et al. have also observed that only $7 \%$ of familial cerebral aneurysms occur at the anterior communicating artery complex. ${ }^{4,9}$ Others have suggested that familial cerebral aneurysms may be more common on the middle cerebral artery while others still have suggested that familial 


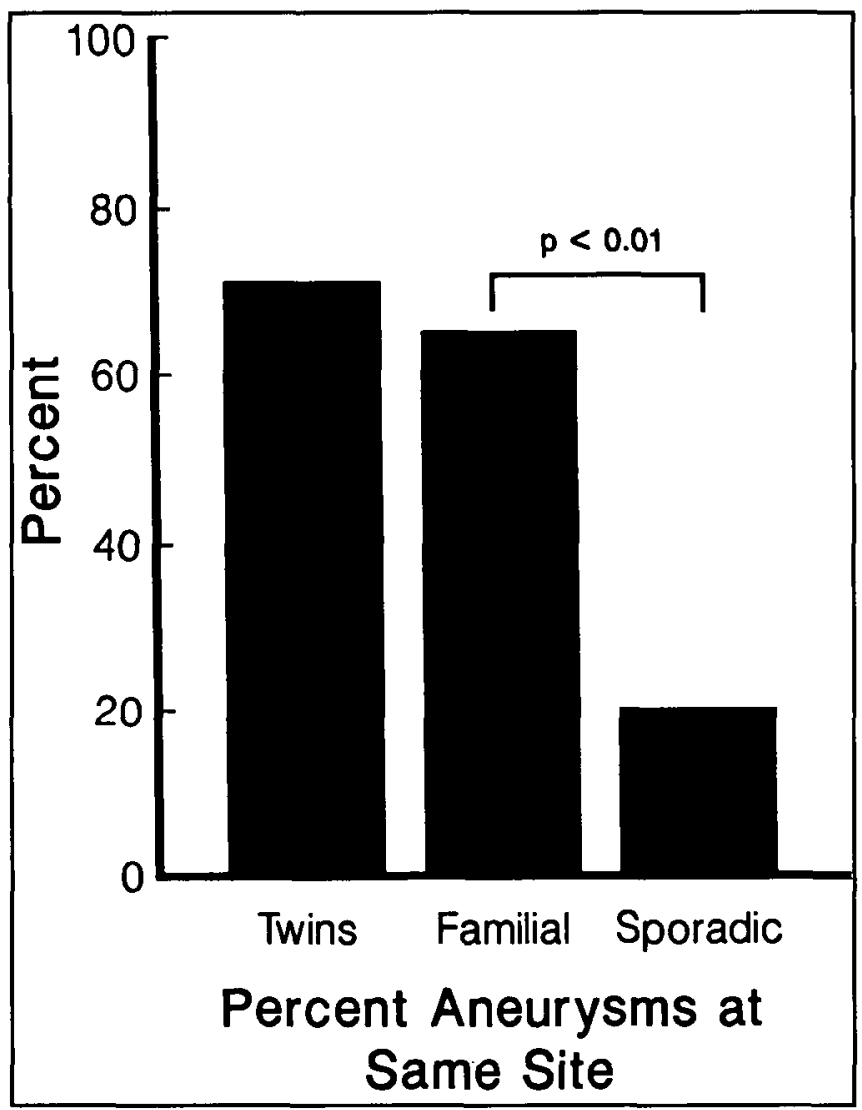

Figure 5: Percentage of familial aneurysms that occur at the same (or at the mirror) site, compared to two randomly chosen pairs of sporadic aneurysms. (Data from Lozano AM and Leblanc R, 1987 and Leblanc $R, 1996^{6.14}$ )

aneurysms may be less frequent on the posterior communicating artery. ${ }^{5.7,9,11}$ Our most recent studies have not confirmed any statistically significant difference in the site of familial cerebral aneurysms compared to sporadic ones. ${ }^{2,13}$ It is interesting to note, however, that in our own data familial cerebral aneurysms occurred at the same or at the mirror site within individuals of the same family in $65 \%$ of cases, significantly higher than the $21 \%$ expected from randomly-selected sporadic aneurysm pairs and very close to the $70 \%$ reported for concordance of site for cerebral aneurysms in twins ${ }^{6,14}$ (Figure 5).

\section{Size of familial cerebral aneurysms}

In a review of the literature we have previously observed that the size of ruptured familial cerebral aneurysms may be smaller than the size of sporadic ruptured aneurysms but this was the case only in women. ${ }^{4}$ Others have also suggested that familial cerebral aneurysms may rupture at a smaller size than sporadic ones. $^{?}$

\section{Outcome of rupture}

The rupture of a familial cerebral aneurysm seems to be associated with a higher burden of death or disability than the rupture of a sporadic aneurysm (Figure 6). In our own patients $50 \%$ of ruptured familial aneurysms resulted in death and $22 \%$ of the patients were neurologically disabled. ${ }^{6}$ Bromberg et al. have also observed a higher risk of death and disability for ruptured familial aneurysms compared to ruptured sporadic

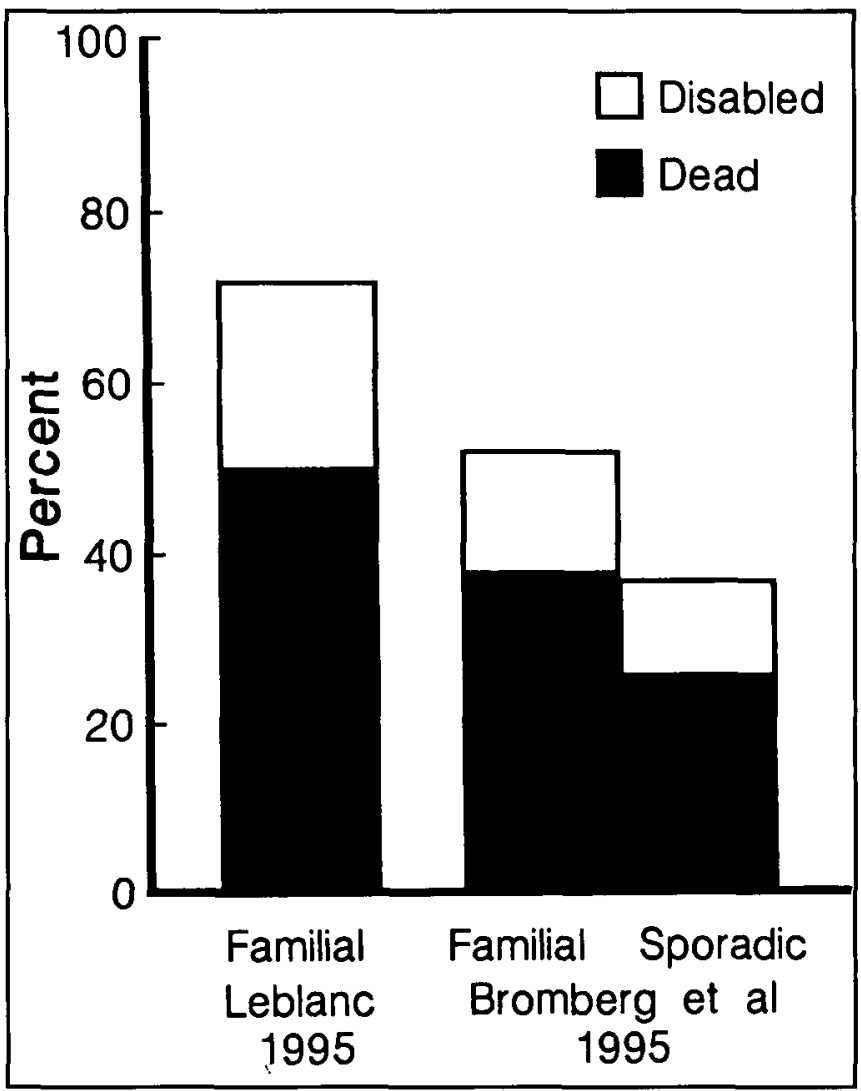

Figure 6: Risk of death or disability for familial cerebral aneurysms.

aneurysms. ${ }^{26}$ Perhaps familial aneurysms are weaker than sporadic ones, producing a more extensive rent at the time of rupture, resulting in a more massive subarachnoid haemorrhage accounting, in turn, for the high mortality and morbidity of rupture. The high risk of death or disability associated with the rupture of a familial aneurysm offers compelling support for the systematic angiographic screening of individuals with a family history of cerebral aneurysms.

\section{Angiographic screening of asymptomatic relatives}

It has been estimated that elective angiographic screening of relatives of patients with a family history of a ruptured cerebral aneurysm will identify an aneurysm in $33 \%$ of siblings and in $29 \%$ of all relatives. ${ }^{9}$ These values which were gleaned from an analysis of reported cases undoubtedly reflect a bias in the reporting of positive cases. In prospective studies Bromberg et al. and Ronkainen et al. have observed a $25 \%$ and $9.5 \%$ yield, respectively, with angiographic screening of relatives. ${ }^{11,26}$ These values are much higher than our own results of $2.4 \% .^{6}$

Ronkainen et al.'s study warrants special mention. ${ }^{27}$ They screened 400 relatives of patients with a ruptured familial cerebral aneurysms using MRA. They identified 37 aneurysms in the 400 screened individuals $(9.5 \%)$. Thirty-two of the 37 patients with a positive MRA then underwent IA-DSA. In 4 of these (12.5\%) the MRA was found to have given a false-positive result, while in another $4(12.5 \%)$ the MRA had given a falsenegative result in that a second aneurysm was identified by IADSA that had not been seen on the MRA examination. These false-positive and false-negative rates are more than of academic 
interest to epidemiologists interested in the prevalence of familial cerebral aneurysms since a false-negative examination would leave a patient at risk of subsequent rupture. It could be argued that since a false-negative examination is more likely to occur with a small aneurysm with a lesser likelihood of rupture, then a false-negative result may not be of significant clinical importance since the patient who harbours the undiagnosed aneurysm would be at a low risk of sustaining a subarachnoid haemorrhage. This contention must, however, be mitigated by the suggestion that familial aneurysms may rupture at a smaller size than do sporadic ones, especially in women. ${ }^{11}$ The possibility that familial aneurysms may develop de novo after negative angiogram is also of concern since instances of such an occurrence are well documented. ${ }^{16}$ The role of 3-dimensional CT angiography as a screening procedure for familial cerebral aneurysms remains to be assessed although it may prove to be superior to MRA in detecting cerebral aneurysms. ${ }^{28}$

The question of screening of asymptomatic relatives has been addressed by decision analyses. ${ }^{29,30}$ These analyses consider the risk of angiography, the risk of surgery, the presumed prevalence rate of familial cerebral aneurysms, the annual rate of rupture of an asymptomatic aneurysm, and the mortality and morbidity associated with rupture. In such a study we have suggested that IA-DSA screening should be undertaken for relatives at risk of harbouring a familial cerebral aneurysm if they have a life expectancy of 32 years or more, corresponding to an age of 49 years in men and of 54 years in women, to achieve a benefit over natural history of at least one year of added life free of neurological sequelae. ${ }^{30}$ We would put the lower limit for the age of screening of asymptomatic relatives at 20 years of age. This figure is arrived at by our previous study which established that only $2.5 \%$ of familial aneurysms ruptured within the first two decades while close to $20 \%$ ruptured within the first three. ${ }^{4}$ Thus, the risk of rupture is small in patients younger than 20 years but, by age 30 , over one-fifth of familial cerebral aneurysms destined to rupture will have done so (three-quarters will have ruptured by age 50 ). It follows that the angiographic screening of individuals younger than 20 years will be of little benefit but that the benefit of screening patients 20 years or older will be increasingly greater. Others have also addressed the question of screening, using a decision analysis approach, with similar findings. ${ }^{29}$ Until the development of a biological marker for cerebral aneurysms, angiography remains the only way to determine the presence or absence of a cerebral aneurysm.

\section{Familial infundibula}

An infundibulum, usually at the origin of the posterior communicating artery, has been reported in up to $7 \%$ of the general population. ${ }^{31}$ In patients with familial aneurysms, however, infundibula can be seen in up to $40 \%$ of cases. ${ }^{32}$ Whether or not infundibula represent pre-aneurysmal dilatation is still debated. Hassler and Saltzmann observed that two-thirds of infundibula studied histologically had a medial defect larger than $1 \mathrm{~mm}$ and that half of these had an associated defect of the elastic lamina, supporting the contention that infundibula are pre-aneurysmal lesions. ${ }^{33}$ Others, unable to verify these findings, have concluded that infundibula are a variant of normal. ${ }^{34}$ There have been reports of the enlargement of an infundibulum to produce a frank "berry" aneurysm. ${ }^{35}$ One of our asymptomatic patients with a family history of cerebral aneurysms was observed to have an infundibulum of the posterior communicating artery that changed its configuration on follow-up angiography to take on a more aneurysmal appearance within one year of the initial angiogram. Thus we would favour repeated yearly screening of patients with a family history of cerebral aneurysms in whom an infundibulum is demonstrated.

\section{Familial conditions associated with cerebral aneurysms}

\section{Collagen vascular diseases}

Cerebral aneurysms have occasionally been noted in patients with Marfan's syndrome, with pseudoxanthoma elasticum, and with type IV Ehler's-Danlos syndrome, although the major cerebrovascular lesions seen in these and other collagen vascular diseases is a carotid cavernous fistula. ${ }^{36-39}$ Largely anecdotal reports of cerebral aneurysms associated with other familial conditions have been reviewed by Schievink et al.; and we have even encountered a family with coexisting familial Graves' disease and cerebral aneurysms. ${ }^{41}$ The demonstration that Ehler'sDanlos syndrome type IV is caused by a relative deficiency of type III collagen and the suggestion that type III collagen may also be deficient in some patients with cerebral aneurysms suggested that a type III collagen deficiency might also be associated with familial cerebral aneurysm and that skin biopsies demonstrating a relative deficiency of type III collagen might identify asymptomatic individuals with a familial cerebral aneurysm. ${ }^{42}$ However, we were unable to demonstrate a deficiency of type III collagen in patients with familial cerebral aneurysms (and in patients with multiple aneurysms) and it has been demonstrated that type III collagen gene is well-preserved in patients with familial and sporadic cerebral aneurysms. ${ }^{44}$ Thus, familial cerebral aneurysms are not associated with a quantitative nor a qualitative abnormality of type III collagen and the typing of collagen by skin biopsy of individuals at risk of harbouring a familial cerebral aneurysm is not informative.

\section{Adult polycystic kidney disease}

Adult polycystic kidney disease is the only genetically-determined condition that has been conclusively associated with cerebral aneurysms. ${ }^{22-24}$ The pathogenic basis of this association is unknown. It is possible that cerebral aneurysms in patients with APKD develop as a passive response to the arterial hypertension that is frequently present in patients with this condition. However up to $25 \%$ of APKD patients with a cerebral aneurysm are normotensive when the aneurysm is diagnosed. ${ }^{23}$ A prospective study of 17 APKD patients asymptomatic for cerebral aneurysms identified 7 patients with an unruptured aneurysm: 2 patients were hypertensive, 5 were not. ${ }^{22}$ Thus, it is possible that cerebral aneurysms in patients with APKD result from a genetically-determined lesion affecting the cerebral blood vessel wall, albeit one on which other factors, such as arterial hypertension, may act. ${ }^{23,25}$ It is possible, therefore, that non-APKD patients with familial cerebral aneurysms may nonetheless have inborn errors affecting cerebral vessels similar to those implicated in APKD, a hypothesis testable by current technology. In support of this hypothesis has been the recent cloning of the APKD gene, polycystin, which is expressed maximally in the kidneys and cerebral blood vessels of affected individuals.

We have observed that cerebral aneurysms in APKD patients 
share similarities with familial cerebral aneurysms: the peak decennial incidence of ruptured APKD-associated aneurysms is in the 5th decade, the mean age of rupture of APKD-aneurysms is younger than of sporadic aneurysms, and three-quarters of APKD-associated aneurysms will have ruptured by age $50 .^{23}$ In contradistinction with familial cerebral aneurysms, however, we have found that APKD-associated aneurysms are more common in males. This, however, has not been confirmed by others. ${ }^{24}$

\section{Tissue antigens}

Human leucocyte antigens (HLA) have been associated with a number of immunological diseases and HLA loci can be coinherited with genes responsible for non-immunological disorders. It has been suggested that HLA loci A-28, B-7, and DR-2 may be associated with cerebral aneurysms. ${ }^{46}$ If this were the case then the identification of these loci in asymptomatic individuals at risk might identify those harbouring a familial cerebral aneurysm. However, we were unable to establish any correlation between the presence or absence of familial cerebral aneurysms and specific HLA loci or haplotypes. ${ }^{6}$ Although HLA B-7 and DR-2 were present in some of our familial patients with cerebral aneurysms they were also present in their relatives who did not have aneurysms. HLA A-28 was absent in all but 1 of the individuals with familial cerebral aneurysms that we tested. Similar results have been observed by others who also failed to confirm that HLA B-7 is coinherited with familial cerebral aneurysms. ${ }^{47}$ One must, therefore, conclude that HLA-typing is not sufficient to identify or exclude family members at risk of harbouring a cerebral aneurysm.

\section{Pattern of inheritance}

The pattern of inheritance of familial cerebral aneurysms is unknown. Cerebral aneurysms have been reported in association with conditions with dominant and recessive inheritance. ${ }^{40} \mathrm{~A}$ study of the pedigrees of our families and of other reported families does not identify a definite mode of inheritance as the data could as well be compatible with dominant, recessive, oligogenic, of multifactorial inheritance. A recent computer model of the mode of inheritance of familial intracranial aneurysms encompassing all pedigrees reported to 1994 suggested that autosomal inheritance, either of a dominant but rare allele, or of a more common but recessive allele best fit the published data ${ }^{40} \mathrm{~A}$ genealogical reconstruction of up to 7 generations of 9 families with cerebral aneurysms from the Saguenay-Lac StJean region of Canada identified 2 common ancestral couples, one married in Québec City in 1660 and the other arriving in La Pocatière in 1700 , initially suggested a recessive pattern of inheritance. ${ }^{48}$ However, a more recent and more extensive study of familial aneurysms in patients from this region could not identify a specific mode of inheritance. ${ }^{12,13}$

Any model of the pattern of inheritance of familial cerebral aneurysms must take into consideration the predominance of women with familial cerebral aneurysms, their occurrence in mothers more frequently than in fathers, in daughters more often than in sons, and in sisters more commonly than in brothers. Further, the role of other possible familial influences such as arterial hypertension and diabetes mellitus, and exposure to common environmental toxins, such as cigarette smoke, alcohol, and the birth control pill may be confounding elements. Thus, the inheritance of cerebral aneurysms may be multifactorial, may exhibit genetic heterogeneity and may have variable expression. Only further advances in molecular neurobiology will cleave this Gordian knot.

\section{Genetic linkage analysis}

The lack of association between familial cerebral aneurysms and the HLA system make it unlikely that familial cerebral aneurysms are linked to a lesion of the short arm of chromosome $6 .{ }^{6}$ Similarly, a lesion of the collagen type III gene has also been excluded as an etiologic factor of importance in familial cerebral aneurysms. ${ }^{43,44}$ The association of cerebral aneurysms with APKD in the absence of arterial hypertension suggests a possible genetically-determined defect or defects of the constituents of the arterial wall as factors in the development of cerebral aneurysms in this condition. ${ }^{23}$ Perhaps a similar defect exists in patients with non-APKD familial cerebral aneurysms, a hypothesis that could be tested by current neurobiological techniques using a candidate gene approach.

Linkage analysis can be especially useful in conditions arising from a defect in a single gene and where simple recessive or dominant inheritance has been demonstrated. Large families with an easily identifiable, rare phenotype offer the best probability of success with genetic linkage analysis. Thus some difficulties with linkage analysis of familial cerebral aneurysms are readily apparent: single gene inheritance has not been demonstrated nor has the pattern of inheritance been identified. Large families in our societies are no longer the norm and cerebral aneurysms are not rare. Finally, the phenotype - the cerebral aneurysm - is only discernible by invasive intra-arterial angiography or by MRA, the latter having a non-negligible false-negative rate.

\section{CONCLUding Remarks}

The recent burgeoning of interest in familial cerebral aneurysms is due to: 1) the availability of MRA which permits the non-invasive evaluation of individuals at risk of harbouring a familial cerebral aneurysm; 2) the desire to identify cerebral aneurysms before they rupture so that they can be treated before a catastrophic haemorrhage occurs; and 3) advances in molecular neurobiology that could identify a putative genetically-determined lesion in familial cases that may shed light on sporadic ones. The main support for a possible genetic etiology of some cerebral aneurysms comes from their clustering within families, from their occurrence in identical twins, and from their association with diseases with a well-defined genetic etiology. ${ }^{4}$ Familial cerebral aneurysms, and the patients who harbour them, have specific characteristics that differentiate them from sporadic cerebral aneurysm patients: they are more frequent in women in whom they rupture at a smaller size and at a younger age than sporadic aneurysms.$^{14}$ Familial aneurysms tend to rupture within the same decade and in the same or mirror sites in individuals from the same family. ${ }^{4.6,14}$ The effects of rupture of a familial cerebral aneurysm seem to be more severe, with a higher risk of death or disability, than the rupture of a sporadic one. ${ }^{6,26}$ Thus, angiographic screening of asymptomatic individuals in whom two or more family members have a proven cerebral aneurysm seems warranted, especially in first degree relatives in whom the risk appears to be greater., ${ }^{9,13,30}$ In the absence of a biological 
marker angiography remains the only reliable way of excluding the presence of a cerebral aneurysm in family members at risk. Intra-arterial digital subtraction angiography is more sensitive than MRA which may have a false-negative rate of over $10 \%$ especially for small aneurysms. ${ }^{27}$

The pattern of inheritance of family cerebral aneurysms is unknown. Autosomal dominant inheritance of a rare allele or autosomal recessive inheritance of a more common allele best fit computer models but genetic heterogeneity, variable penetrance, and multifactorial influences have not been excluded. ${ }^{40}$

Identifying asymptomatic familial aneurysms is best achieved by cerebral angiography. In our decision analysis model the small risk of angiography was not a significantly sensitive parameter in the overall outcome, so that replacing IADSA with MRA insignificantly decreased the overall risk of intervention. ${ }^{30}$ The female sex, arterial hypertension, the use of anovulants, cigarette smoking, and the drinking of alcohol have been identified as risk factors for subarachnoid haemorrhage and should, therefore, be taken into account when considering elective screening of individuals at risk of harbouring a familial aneurysm. ${ }^{49}$ Thus, radiological screening may be of greater benefit to women than to men. Arterial hypertension may promote the formation of aneurysms or their rupture and may produce a more severe subarachnoid haemorrhage with worse outcome. Thus, the presence of arterial hypertension may be a further incentive for screening individuals at risk. Current or past use of anovulants may also be an added incentive to screen those individuals who also have a family history of aneurysms. This is especially the case if they also smoke cigarettes as these two risk factors appear to be synergistic for subarachnoid haemorrhage. ${ }^{49}$ In the absence of a biological marker cerebral angiography should be considered for first degree relatives especially older than 20 years of age. Perhaps familial cerebral aneurysms will be shown to have a high incidence of $(x-1$ antitripsin deficiency (as is the case for some $16 \%$ of individuals with a sporadic cerebral aneurysm) which could help to select patients at risk of harbouring a cerebral aneurysm for angiography. ${ }^{50}$

\section{REFERENCES}

1. Yoshimoto B. Blood and Water. In: Lizard, Washington Square Press, New York, 1993: 93-121.

2. Stehbens WE. Review article. Etiology of intracranial berry aneurysms. J Neurosurg 1989: 70-823.

3. Forbus WD. On the origin of the miliary aneurysm of the superficial cerebral arteries. Bull Johns Hopkins Hosp. 1930; 47: 239-284.

4. Lozano AM, Leblanc R. Familial intracranial aneurysms. J Neurosurgery 1987; 66: 522-528.

5. Norrgård O. Ängquist K-A, Fodstad $\mathrm{H}$, Forsell $\AA$, Lindberg $\mathrm{M}$. Intracranial aneurysms and heredity. Neurosurgery 1987; 20: 236239.

6. Leblanc R, Melanson D, Tampieri D, Guttmann RD. Familial cerebral aneurysms: a study of 13 families. Neurosurgery 1995; 37: 633-639.

7. Ronkainen A, Hernesniemi J, Tromp G. Special features of familial intracranial aneurysms: report of 215 familial aneurysms. Neurosurgery 1995; 37: 43-47. (?1993)

8. Wang PS, Lonstretch WT, Koepsell TD. Subarachnoid hemorrhage and family history. Arch Neurol 1995; 52: 202-204.

9. Schievink WI, Schaid DJ, Michels VV, Piepgras DG. Familial aneurysmal subarachnoid hemorrhage: a community based study. J Neurosurg 1995; 83: 426-429.

10. Bromberg JEC, Rinkel GJE, Algra A, Greebe P, et al. Subarachnoid hemorrhage in first and second degree relatives of patients with subarachnoid hemorrhage. $\mathrm{Br}$ Med J 1995; 311: 288-289.
11. Bromberg JEC, Rinkel JE, Algra A, et al. Familial subarachnoid hemorrhage: distinctive features and patterns of inheritance. Ann Neurol 1995; 38: 929-934.

12. Mathieu J, Pérusse L, Allard P, et al. Epidemiological study of ruptured intracranial aneurysms in the Saguenay-Lac St-Jean region (Québec, Canada). Can J Neurol Sci 1996; 23: 184-188.

13. De Braekeleer M, Pérusse L, Cantin L, Bouchard J-M, Mathieu J. A study of inbreeding and kinship in intracranial aneurysms in the Saguenay-Lac St-Jean region (Québec, Canada). Ann Hum Genet 1996; 60: 99-104.

14. Leblanc R. Familial cerebral aneurysms: a bias for women. Stroke 1996; 27 : 1050-1054.

15. O'Brien JG. Subarachnoid haemorrhage in identical twins. Br Med J 1942; 1: 607-609.

16. Brisman $\mathrm{R}$, Abbassioun K. Familial intracranial aneurysms. J Neurosurg 1971; 34: 678-682.

17. Fairburn B. 'Twin' intracranial aneurysms causing subarachnoid haemorrhage in identical twins. Br Med J 1973; 1: 210-211.

18. Schon F, Marshall J. Subarachnoid haemorrhage in identical twins. J Neurol Neurosurg Psychiatry 1984; 47: 81-83.

19. Weil SM, Olivi A, Greiner AL, Tobler WD. Multiple intracranial aneurysms in identical twins. Acta Neurochir (Wien) 1988; 95 : 121-125.

20. Parekh HC, Gurusinghe NT, Sharma RR. Cerebral berry aneurysms in identical twins: a case report. Surg Neurol 1992; 38: 277-279.

21. Wilson PJE, Cast IP. 'Twin' intracranial aneurysms. Br Med J 1973; 1: 484. Letter.

22. Wakabayaski T, Fujita S, Ohbora Y, et al. Polycystic kidney disease and intracranial aneurysms. Early angiographic diagnosis and early operation for the unruptured aneurysm. J Neurosurg 1983; 58: 488-491.

23. Lozano AM, Leblanc R. Cerebral aneurysms and polycystic kidney disease: a critical review. Can J Neurol Sci 1992; 19: 222-227.

24. Schievink WI, Torres VE, Piepgras DG, Wiebers DO. Saccular intracranial aneurysms in autosomal dominant polycystic kidney disease. J Am Soc Nephrol 1992; 3: 88-95.

25. Leblanc R. Heredity and etiology of intracranial berry aneurysms. Stroke 1997; letter in press.

26. Bromberg JEC, Rinkel GHE, Algra A, Limburg N, Van Gijn J. Outcome in familial subarachnoid hemorrhage. Stroke 1995; 26: 961-963.

27. Ronkainen A, Puranen MI, Hernesnigmi JA, et al. Intracranial aneurysms, MR angiographic screening in 400 asymptomatic individuals with increased familial risk. Radiology 1995; 195: $35-40$

28. Tampieri D, Leblanc R, Oliszek J, et al. 3-D CT angiography of cerebral aneurysms. Neurosurgery 1995; 36: 749-755.

29. Dippel DWJ, ter Berg JWM, Habbena JDF. Screening for unruptured familial intracranial aneurysms. A decision analysis. Acta Neurol Scand 1992; 86: 381-389.

30. Leblanc R, Worsley KJ, Melanson KJ, Tampieri D. Angiographic screening and elective surgery of familial cerebral aneurysms: a decision analysis. Neurosurgery 1994; 35: 9-14.

31. Saltzmann GF. Infundibular widening of the posterior communicating artery studies by carotid angiography. Acta Radiol 1959; 51: 415-421.

32. Edelsohn L, Caplan L, Rosenbaum AE. Familial aneurysm and infundibular widening. Neurology 1972; 22: 1056-1060.

33. Hassler O, Saltzmann GH. Angiographic and histological changes in infundibular widening of the posterior communicating artery. Acta Radiol [Diagn] (Stockh) 1963; 1: 321-327.

34. Epstein F, Ransohoff $\mathbf{J}$, Budzilovich GB. The clinical significance of junctional dilatation of the posterior communicating artery. $\mathrm{J}$ Neurosurg 1970; 33: 529-531.

35. Appleby PD. Infundibular widening of the posterior communicating artery progressing to true aneurysm. Br J Radiol 1983; 56: 59-60.

36. Finney HL, Roberts TS, Anderson RE. Giant intracranial aneurysm associated with Marfan's syndrome. Case report. J Neurosurg 1976; 45: 342-347.

37. Fox J. Intracranial Aneurysms. New York: Springer-Verlag, 1983, Vol 1: pp 406-408.

38. Rubinstein MK, Cohen NH. Ehlers-Danlos syndrome associated with multiple intracranial aneurysms. Neurology 1964; 14: 125-132. 
39. Kissel P, Arnould G, André JM. Incidences des accidents vascular cérébraux au cours des conjonctivo-dysplasies héréditaires. J Gent Hum 1972; 20: 151-167.

40. Schievink WI, Schaid J, Rogers JM, Piepgras DG, Nichels VV. On the inheritance of intracranial aneurysms. Stroke 1994; 25: 2028-2037.

41. Leblanc R, Lozano AM. Grave's disease and subarachnoid hemorrhage: a possible familial association. Can J Neurol Sci 1987; 14: 638-641.

42. Neil-Dwyer G, Barlett JR, Nicholls AC, et al. Collagen deficiency and ruptured cerebral aneurysms. A clinical and biochemical study. J Neurosurg 1983; 59; 16-20.

43. Leblanc R, Lozano AM, Van der Rest M, Guttmann RD. Absence of collagen deficiency in familial cerebral aneurysms. J Neurosurg 1989; 70: 837-840.

44. Kuivaniemi H, Prockop DJ, Wu U, et al. Exclusion of mutations in the gene for type III collagen (COL3A1) as a common cause of intracranial aneurysms or cervical artery dissections by sequence analysis of coding sequence of type III collagen in 55 unrelated patients. Neurology 1993; 43: 2652-2658.
45. Ostergaard JR, Bruun-Petersen G, Lamm LU. HLA antigens and complement types in patients with intracranial saccular aneurysms. Tissue Antigens 1986; 28: 176-181.

46. Norrgård O, Beckman G, Beckman L, et al. Genetic markers in patients with intracranial aneurysms. Hum Hered 1987; 37: 225259.

47. Mellergård $P$, Ljunggren $B$, Brandt L, Johnson U, Holtås S. HLAtyping in a family with six intracranial aneurysms. Br J Neurosurg 1989; 3: 479-486.

48. Cantin L, Mathieu J. Debraekeleer M, Vigneault A. Anévrysmes intracrâniens familiaux: étude de 9 familles saguenéenes. Can J Neurol Sci 1988; 15: 94 (Abstr).

49. Longstreet WT, Koepsell TD, Yerby MS, Van Belle G. Risk factors for subarachnoid hemorrhage. Prog Rev Stroke 1985; 16: 377385.

50. Schievink WI, Katzmann JA, Piepgras DG, Schaid DJ. Alpha-1antitrypsan phenotypes among patients with intracranial aneurysms. J Neurosurg 1996; 84: 781-784. 